\title{
Left Ventricular Ejection Fraction
}

National Cancer Institute

\section{Source}

National Cancer Institute. Left Ventricular Ejection Fraction. NCI Thesaurus. Code C99524.

The fraction of the left ventricular end diastolic volume ejected with each beat. The left ventricular ejection fraction is equal to the left ventricular stroke volume divided by the left ventricular end diastolic volume. 